\title{
THE CORNELL MEDICAL INDEX IN DISABILITY EVALUATION
}

\author{
BY \\ CLARKE STOUT, M.D. \\ Assistant Professor, Departments of Pathology and Medicine \\ MARY ANN WIGHT \\ Sophomore Medical Student \\ AND \\ JOHN G. BRUHN, Ph.D. \\ Associnte Professor of Sociology in Medicine \\ University of Oklahon: $z$ Medical Center, Oklahoma City, Oklahoma, U.S.A.
}

The evaluation of persons seeking financial support because of disability due to physical or emotional illness is often difficult. Although definite guidelines have been established to assist in the determination of the degree of impairment from various diseases (Social Security Regulations, 1968) and orthopaedic abnormalities (Committee on Medical Rating of Physical Impairment, 1958), little has been accomplished in this area in patients whose problems are not as easily defined. It has been suggested (Social Security Regulations, 1968) that the MMPI, or a similar psychological measurement, might be useful in the resolution of some of the latter cases. However, the time and personnel required for the completion of such tests would probably be prohibitive. The Cornell Medical Index (CMI) (Brodman, Erdmann, and Wolff, 1956), on the other hand, can be filled out in a few minutes, does not require specialized personnel for its administration or interpretation, and yields both medical and psychological information. The present study attempts to determine the feasibility of the CMI as an adjunct in disability evaluation.

\section{MATERIALS AND MethodS}

In 1958, the University of Oklahoma Medical Center assumed responsibility for the evaluation of persons seeking to qualify for Public Assistance. Patients were referred for examination at the Work Evaluation Clinic (WEC) only after their local physicians and employees of the Department of Public Welfare were unable to determine eligibility. One to three candidates were seen daily, at which time a complete history was obtained and physical examination was carried out, usually by resident and junior staff physicians from the Department of Medicine. Patients were given the CMI to complete prior to their arrival at the WEC. The test was described as a means to help the doctor in his evaluation. Assistance was given to those patients who could not read. Indicated $x$-ray and laboratory studies were obtained and reviewed, and the final summation of each case was completed by the director of the Student Health Service at the Medical Center. Depending upon the findings, persons were classified into three categories: (1) permanently disabled; (2) temporarily disabled; or (3) not disabled. This information was then sent to the Department of Public Welfare, which made the final decision in each case.

The CMI has been described at length in the literature (Brodman et al., 1956; Weider, Brodman, Mittlemann, Wechsler, and Wolff, 1946; Brodman, Erdmann, Lorge, and Wolff, 1949; Brodman, Erdmann, Lorge, and Wolff, 1951; Brodman, Erdmann, Lorge, Gershenson, and Wolff, 1952). Briefly, it is a health questionnaire containing 195 questions which are written in colloquial language and are similar to those that might be asked in a comprehensive medical interview. Most of the first 144 questions are related to present and past medical illness (Medical questions), and are grouped according to organ systems; the remaining 51 questions concern mood and feeling patterns (Psychological questions).

A random sample of 739 patients was selected from a total of 2,952 consecutive visitors to the WEC between 23 November 1960 and 12 January 1967. 
Of these 739 persons, 603 had completed CMIs which were suitable for analysis. The characteristics of the final sample population are shown in Table I.

TABLE I

CHARACTERISTICS OF THE SAMPLE POPULATION WHOSE CMIS WERE ANALYSED

\begin{tabular}{l|c|c|c}
\hline & Males & Females & Totals \\
\cline { 2 - 3 } $\begin{array}{l}\text { Mean education (years) } \\
\text { Mean age }\end{array}$ & $9 \cdot 3$ & $11 \cdot 8$ & \\
Age groups & 53.9 & $51 \cdot 1$ & \\
$\begin{array}{c}35-45 \\
45-54\end{array}$ & 34 & 6 & \\
$55-64$ & 54 & 11 & 40 \\
$>65$ & 135 & 69 & 65 \\
& 186 & 107 & 204 \\
& 1 & - & 1 \\
\hline
\end{tabular}

TABLE II

NUMBER OF POSITIVE RESPONSES ON THE CMI BY SEX

\begin{tabular}{c|c|c}
\hline No. of Positive Responses on CMI & Males & Females \\
\cline { 2 - 3 } $0-19$ & 3 & - \\
$20-29$ & 6 & 1 \\
$30-39$ & 17 & 5 \\
$40-49$ & 28 & 18 \\
$50-59$ & 51 & 17 \\
$60-69$ & 61 & 25 \\
$>70$ & 244 & 127 \\
\hline & 410 & 193 \\
\hline
\end{tabular}

\section{RESULTS}

Table II shows the total number of positive responses to the 195 questions on the CMI by sex. It is interesting that only 10 persons $(1.7 \%)$, nine males and 1 female, answered yes to less than 30 questions, and of these, only three responded to less than 20 . Over half (61\%) of the group answered yes to 70 or more questions. Chi-square analysis revealed no significant difference between the sexes in the total number of yes responses.

The breakdown of the group according to disability is shown in Table III. An analysis of variance between the degree of disability and the number of positive responses on the CMI was carried out. It is interesting that there were no significant differences in the frequency of yes responses by sex and disability group for either the medical, psychological, or total questions (Table III). Moreover, when each of the 195 questions was analysed according to degree of disability, a significant difference was found for only five of the questions. No particular pattern was evident on examination of these five questions, and it is likely that the associations were simply due to chance.

In Table IV, correlation coefficients were computed for the entire group using the factors of age, education, and number of positive responses to medical, psychological, and total questions on the CMI. Although the values were not statistically significant, it is interesting that education was negatively related to the number of positive responses to medical, psychological, and total questions. The positive correlations between medical, psychological, and total questions were anticipated in view of the large number of positive responses in each category.

TABLE III

PROPORTION OF POSITIVE RESPONSES TO THE MEDICAL, PSYCHOLOGICAL, AND TOTAL QUESTIONS ON THE CMI BY DISABILITY AND SEX

\begin{tabular}{|c|c|c|c|c|c|}
\hline Disability & Sex & $\mathbf{N}$ & Medical Questions & $\begin{array}{l}\text { Psychological } \\
\text { Questions }\end{array}$ & Total Questions \\
\hline Permanently disabled & $\stackrel{\mathbf{M}}{\mathbf{F}}$ & $\begin{array}{l}66 \\
43\end{array}$ & $\begin{array}{l}0.69 \\
0.70\end{array}$ & $\begin{array}{l}0.48 \\
0.43\end{array}$ & $\begin{array}{l}0.67 \\
0.65\end{array}$ \\
\hline Temporarily disabled & $\stackrel{\mathbf{M}}{\mathbf{F}}$ & $\begin{array}{l}51 \\
20\end{array}$ & $\begin{array}{l}0.69 \\
0.75\end{array}$ & $\begin{array}{l}0.46 \\
0.57\end{array}$ & $\begin{array}{l}0.65 \\
0.72\end{array}$ \\
\hline \multirow[t]{2}{*}{ Not disabled } & $\begin{array}{l}\mathbf{M} \\
\mathbf{F}\end{array}$ & $\begin{array}{l}293 \\
130\end{array}$ & $\begin{array}{l}0.70 \\
0.68\end{array}$ & $\begin{array}{l}0.52 \\
0.52\end{array}$ & $\begin{array}{l}0.67 \\
0.66\end{array}$ \\
\hline & & 603 & 0.70 & 0.50 & 0.67 \\
\hline
\end{tabular}

TABLE IV

CORRELATION COEFFICIENTS BETWEEN THE VARIABLES OF AGE, EDUCATION, AND THE NUMBER OF POSITIVE RESPONSES TO MEDICAL, PSYCHOLOGICAL, AND TOTAL QUESTIONS ON THE CMI

\begin{tabular}{|c|c|c|c|c|c|}
\hline & Age & Education & Medical Questions & $\begin{array}{c}\text { Prychological } \\
\text { Questions }\end{array}$ & Total Questions \\
\hline $\begin{array}{l}\text { Age } \\
\text { Education } \\
\text { Medical questions } \\
\text { Psychological questions } \\
\text { Total questions }\end{array}$ & $=$ & $\begin{array}{l}0.040 \\
= \\
=\end{array}$ & $\begin{array}{c}0.093 \\
-0.008 \\
- \\
-\end{array}$ & $\begin{array}{c}-0.027 \\
-0.015 \\
0.590 \\
-\end{array}$ & $\begin{array}{r}0.051 \\
-0.012 \\
0.934 \\
0.840 \\
-\end{array}$ \\
\hline
\end{tabular}




\section{Discussion}

The CMI has been useful in a number of situations. In private and hospital medical practice, and in other instances where the rapid collection of a large body of easily evaluated medical and psychological information is necessary, the CMI has proved both accurate and efficient. It has also been used effectively to screen job applicants for evidence of emotional instability (Erdmann, Brodman, Deutschberger, and Wolff, 1953; Brodman, Erdmann, Lorge, Deutschberger, and Wolff, 1954) and to pinpoint areas of difficulty in patients with professed psychiatric problems. In epidemiological studies, the CMI has been a valid indicator of overall medical and emotional health, albeit somewhat less accurate in the identification of specific disorders (Abramson, Terespolsky, Brook, and Kark, 1965).

In general, a positive response to more than $\mathbf{3 0}$ questions on the CMI is indicative of emotional illhealth (Brodman et al., 1952; Abramson et al., 1965). In screening job applicants at a cigarette factory, Erdmann et al. (1953) found that 4\% of 201 women and none of 205 men answered 30 or more questions affirmatively. However, in a random sample of ostensibly healthy New Yorkers, the percentages were considerably higher, being $30 \%$ and $10 \%$ respectively (Brodman et al., 1952). In sick populations, the number of persons responding positively to more than 30 questions rises correspondingly, reaching levels of $70 \%$ to $80 \%$ in patients with documented emotional disturbances (Brodman et al., 1952; Brodman et al., 1954; Brown and Fry, 1962; Lawton, 1959; Arnhoff, Strough, and Seymour, 1956). In the present study, $98 \%$ of the patients responded affirmatively to 30 or more questions on the CMI. This remarkable number of positive responses exceeds that in all studies recorded in the literature in which more than 50 persons were included in the samples. Only the group of $\mathbf{3 7 1}$ veteran neuropsychiatric out-patients reported by Brodman et al. (1952) approaches the figure, with $76 \%$ responding to 30 or more questions with positive answers. In the latter group, however, only $20 \%$ answered 70 or more questions affirmatively, as compared to $61 \%$ of the patients in the present study.

The reason for such a plethora of positive responses among the present group of patients is not clear although it is certainly plain that negative answers would imply lack of illness, and thereby unfavourably prejudice the decision as to the extent of disability. The extraordinary lack of difference among these patients, when CMI scores were compared with the degree of disability, tends to support the latter interpretation. It is noteworthy that the converse was true in a study of job applicants (Erdmann et al., 1953) whose chances for employment might be adversely affected by a large number of positive responses. These applicants responded positively to a significantly smaller number of questions than members of the general population.

In defence of the present patients, it should be noted that the laws of the State of Oklahoma are such that financial need becomes acute in several common situations. For example, families who are without fathers receive public assistance until the youngest child reaches the age of 18. At this point the mother finds herself suddenly without funds at an age when employment is not easily secured. The wives of disabled husbands encounter a similar predicament when the husband dies before the wife has reached the age required (65) to qualify for funds under the Old Age Assistance Programme. Furthermore, men who are unskilled labourers often find that such jobs become difficult to obtain and difficult to perform as long as 10 to 15 years prior to retirement under Old Age Assistance. Many of the patients examined in the present study fit into one of the above described categories, and a number of these people had been unable to qualify for assistance under the more stringent Social Security Disability Regulations.

In conclusion, the CMI is not a satisfactory adjunct in the evaluation of patients seeking payment for disability as outlined above. Furthermore, a query of the examining physicians revealed that the CMI was not helpful in establishing a medical or psychological diagnosis, primarily because so many questions were answered positively.

\section{Summary}

The Cornell Medical Index (CMI) was used as an adjunct in the evaluation of patients seeking public assistance because of physical or emotional illness. Of 603 patients studied, $98 \%$ responded positively to 30 or more questions on the CMI, and $61 \%$ responded positively to $\mathbf{7 0}$ or more questions. Patients did not differ significantly when age, education, and degree of disability were compared with the number of positive responses to medical, psychological, and total questions on the CMI. Furthermore, the plethora of positive answers rendered the CMI useless in terms of its ability to complement the history and physical examination. It was concluded that the CMI is not helpful as an adjunct in the evaluation of such patients.

The assistance of Drs. John McCoy and Gary Haskins, of the Computer Facility, University of Oklahoma Medical Center, is gratefully acknowledged. 
Supported in part by grants HE-08725 and HE-06286 from the National Heart Institute, United States Public Health Service.

\section{REFERENCES}

Abramson, J. H., Terespolsky, L., Brook, J. G., and KARK, S. L. (1965). Cornell Medical Index as a health measure in epidemiological studies. Brit. J. prev. soc. Med., 19, 103.

Arnhoff, F. N., Strough, L. V. C., and Seymour, R. B. (1956). The Cornell Medical Index in a psychiatric outpatient clinic. J. clin. Psychol., 12, 263.

Brodman, K., ErdmanN, A. J., and WolfF, H. G. (1956). Cornell Medical Index Health Questionnaire (Manual), rev. ed. Cornell University Medical College, New York.

-,- , LORGE, I., and WoLfF, H. G. (1949). The Cornell Medical Index. An adjunct to medical interview. J. Amer. med. Ass., 140, 530.

Index-Health Questionnaire II. As a diagnostic
instrument. Ibid., 145, 152. $\longrightarrow,-,-$ Gershenson, C. P., and WoLfF, H. G. (1952). The Cornell Medical Index-Health Questionnaire. III. The evaluation of emotional disturbances. J. clin. Psychol., 8, 119.
- Deutschberger, J., and WolfF, H. G. (1954). The Cornell Medical Index-Health Questionnaire. VII. The prediction of psychosomatic and psychiatric disabilities in Army training. Amer. $J$. Psychiat., 111, 37.

Brown, A. C., and Fry, J. (1962). The Cornell Medical Index-Health Questionnaire in the identification of neurotic patients in general practice. J. psychosom. Res., $6,185$.

Committee on Medical Rating of Physical ImpairMENT. A Guide to the Evaluation of PermanentImpairment of the Extremities and Back. Special edition. J. Amer. med. Ass., 166, February 15, 1958.

ErdmanN, A. J., Brodman, K., DeUtschibrrger, J., and WolfF, H. G. (1953). Health questionnaire use in an industrial medical department. Industr. Med. Surg,. 22, 355.

LAWTON, M. P. (1959). The screening value of the Cornell Medical Index. J. cons. Psychol., 23, 352.

SOCIAL SECURTYY REgULATIONS: Rights and benefits based on disability, Regulations No. 4, Subpart P. Department of Health, Education and Welfare, Social Security Administration, August 1968.

Weider, A, Brodman, K., Mittlemann, B., Wechsler, D., and WolfF, H. G. (1946). The Cornell Index. A method for quickly assaying personality and psychosomatic disturbances, to be used as an adjunct to interview. Psychosom. Med., 8, 411. 